\title{
Sawing off the branch you are sitting on
}

\author{
Markus A. Pöchtrager \\ University of Vienna \\ markus.poechtrager@univie.ac.at
}

\begin{abstract}
This article argues that vowel reduction can be insightfully understood by reinterpreting openness as structural instead of melodic (i.e., mediated by an element). This allows for a unified account of various reduction phenomena in different languages and also extends to lenition in consonants. The proposal made here is couched within Government Phonology 2.0, a further development of Government Phonology.
\end{abstract}

Keywords: vowel reduction; structure; melody; vowel representations; Government Phonology 2.0.

\section{Introduction}

Vowel reduction provides us with valuable insights into the internal structure of vowels. It can easily be expressed in theories that employ unary melodic primes (such as Government Phonology, GP; references to follow) and, as such, vowel reduction is often presented as convincing evidence for the essential correctness of such an approach. As a somewhat simplistic example, we might find a vowel like $e$ (containing primes such as the elements $\mathbf{A}$ and $\mathbf{I}$ ) that reduces to $i$ (I by itself) in unstressed position. This is easily expressed as the loss of $\mathbf{A}$ in prosodically weak position, cf. Harris (1997) for discussion of the link between target and trigger. Put differently, the internal structure of a sound restricts how it can break down under reduction. In contrast, in a system with binary features, there will have to be a random rewriting of features that adds nothing to our understanding of why it is exactly the features in question that are rewritten. This difference in empirical content has long been known; cf. Harris (1997); Harris \& Lindsey $(1995 ; 2000)$ for detailed argumentation. What is crucial is that vowel reduction directly translates into a loss of elements, into a loss of information, as Harris (2005) puts it.

Closer inspection makes clear, however, that not everything is as simple. In this article I will look at three problematic issues that have so far not received a satisfactory solution in the GP literature. Two of them 
will have to do with the understanding of vowel reduction as the loss of phonological material, while the third one has to do with cross-linguistic variation.

In order to set the scene, consider the following two charts summarising vowel reduction in (one variety of) Brazilian Portuguese (Cristófaro Alves da Silva 1992; Mateus \& d'Andrade 2000; Wetzels 1995) and Eastern Catalan (Harris 2005; Wheeler 2005).

(1) Brazilian Portuguese (BP)

\begin{tabular}{lr|c|c|c|c|c|c|c} 
a. & stressed & $i$ & $e$ & $\varepsilon$ & $a$ & $\supset$ & $o$ & $u$ \\
\hline b. & prestressed & $i$ & $e$ & $a$ & $o$ & $u$ \\
\hline c. & unstressed final & \multicolumn{2}{|c|}{$i$} & ə & \multicolumn{2}{|c}{$u$}
\end{tabular}

(2) Eastern Catalan (EC)

$$
\begin{array}{r|c|c|c|c|c|c|c}
\text { strong } & i & e & \varepsilon & a & \jmath & o & u \\
\hline \text { weak } & i & \multicolumn{2}{|c|}{\partial} & \multicolumn{2}{|c}{u}
\end{array}
$$

Notice that in BP (1) the reduction pattern of the front (unrounded) vowels mirrors that of the back rounded vowels. In stressed position all seven vowels can be found (1a), including a contrast between open-mid and closemid. This option is eliminated in prestressed position (i.e., in a position preceding the stressed one) in front and back vowels alike (1b), in favour of the close-mid vowels. A further reduction takes place in the unstressed final position, again with the front vowels being a mirror image of the back vowels (1c). This is in stark contrast to EC, where the mid front vowels merge as schwa (together with [a]), while the back rounded vowels all merge as $[\mathrm{u}]$. The system of reduction is somewhat lopsided, and not as symmetric as that of BP.

The next question is then how to express vowel reduction formally. While (1b) allows for both [e] and [i], that difference is lost in (1c) and we only find [i]; similarly for the back rounded vowels. This, as we had said before, can easily be expressed as the loss of $\mathbf{A}$.

Let us make this more specific. Many versions of GP employ the three elements $\mathbf{A}, \mathbf{I}$, and $\mathbf{U}$ to characterise basic vowel qualities, often allowing for a difference in the weighting of those elements. In (3), [e] is represented as $(\{\mathbf{A}\} \mathbf{I})$, i.e., with $\mathbf{I}$ as the head and $\mathbf{A}$ as the operator (=non-head). Vowel reduction involves the loss of $\mathbf{A}$, leading to a merger with [i] that only has I (as the head). 
(3) Merger of $[\mathrm{e}]$ and $[\mathrm{i}]$

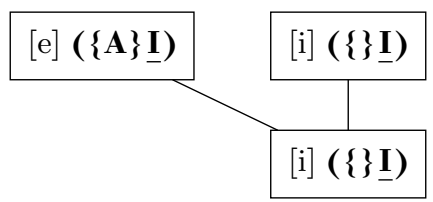

However, what then about the merger of the mid-vowels as high-mid $([\varepsilon] /[\mathrm{e}]$ merge as $[\mathrm{e}],[\mathrm{o}] /[\mathrm{o}]$ as $[\mathrm{o}])$, as can be seen in (1a) vs. (1b)? Two analyses are conceivable for the vowel $[\varepsilon]:(\{\mathbf{I}\} \underline{\mathbf{A}})$ (with $\mathbf{A}$ as the head and $\mathbf{I}$ as the operator) or ( $\{\mathbf{I}, \mathbf{A}\})$ (with no head). Both options are shown in (4).

(4) Merger of $[\varepsilon]$ and $[\mathrm{e}]$
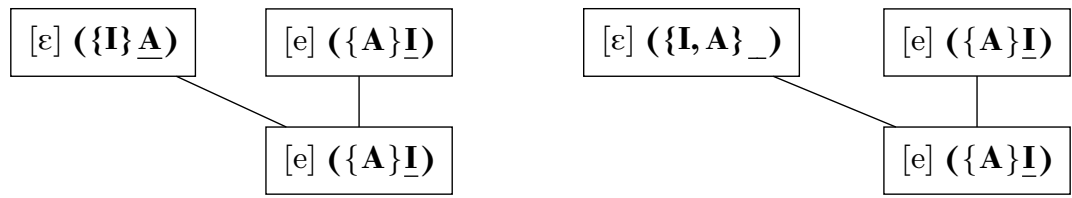

In order to go from either one to [e], i.e., $(\{\mathbf{A}\} \underline{\mathbf{I}})$, a rearrangement of elements is necessary. Either head and operator have to be switched, or an operator has to be made head. This is quite different from (3), as neither option in (4) involves the loss of an element.

We can then sum up the three issues we have encountered so far as follows: Firstly, why do loss of an element and rearrangement of elements both "count" as the same, i.e., as vowel reduction? What is the formal link? Secondly, if rearrangements are indeed allowed, then why do BP $[\varepsilon]$ and [e] not merge as $[\varepsilon]$, which would simply be a different rearrangement? The same reduction pattern can be found in Italian and Slovenian, and seems to be more than just chance. ${ }^{1}$ Thirdly, what about the asymmetries in reduction patterns between languages that we saw when comparing $\mathrm{BP}$ and EC? Why is BP symmetrical while EC is lopsided?

The ambitious goal of this paper will be to address all three problems in one fell swoop by linking everything to structure and the arrangement of elements within that structure.

\footnotetext{
${ }^{1}$ We will look at one pattern that seems to contradict this claim in section 4.4.
} 


\section{The structural view and the element $A$}

Let us begin with the problem illustrated in (3) vs. (4): Why should the reduction of $[\mathrm{e}] \rightarrow[\mathrm{i}]$ (loss of an element) count as much as $[\varepsilon] \rightarrow[\mathrm{e}]$ (change of headedness)? What is the formal link between the two?

In a recent discussion of vowel reduction, Backley $(2011,54)$ states that "reduction causes long to become short, compound to become simplex, and headed to become non-headed." Compound expressions are those that contain more than one element, which, by reduction, would lose all but one, making them simplex. A headed expression becoming non-headed would be $(\{\} \mathbf{I})$ turning into $(\{\mathbf{I}\} \quad$ ), i.e., a tense [i] turning into lax [I]. Now, to that list we could simply add the rearrangement of elements (which "headed turning into non-headed" would be a special case of). It is clear, however, that neither the original operations from Backley's list, nor the newly added rearrangement of elements, would share any formal property. There is possibly some intuitive appeal to that particular set of changes, but their commonality remains mysterious from the point of view of formalism.

In what follows I shall argue that the key lies in Backley's first example: "long to become short". For example, Estonian (Lehiste 1965; Pöchtrager 2006; Raun \& Saareste 1965) allows for three degrees of vowel length in stressed position (short, long, overlong), but only one (short) in unstressed position. This can be taken as the model on which to base the other cases.

In order to do that, we have to make a short detour to discuss the element A, which characterises non-high vowels as well as coronal consonants (Broadbent 1991; Cyran 1997). A behaves differently from other elements, as has also been noted in related models such as Dependency Phonology and Particle Phonology (Anderson \& Ewen 1987; Cobb 1995; 1997; Kaye 2000; Pöchtrager 2006; 2012; Schane 1984). As a result of this, attempts have been made to replace $\mathbf{A}$ by structure within GP 2.0 (Kaye \& Pöchtrager 2009; Pöchtrager \& Kaye 2013; Pöchtrager 2006; 2009b; 2010; $2012 ; 2017 \mathrm{a})$. This is motivated by one property that always seems to go along with $\mathbf{A}$ : it seems to provide extra room (broadly speaking). The patterns are extremely intricate and their interpretation is not always without problems, but the general message seems clear. For example, in English a long vowel before a coda-onset cluster is possible if both consonants contain $\mathbf{A}$, i.e., if they are coronal: count, wound, paint are possible, ${ }^{*}$ coump or * counk are not. Likewise, we find east, boost, haste, boast, etc. but no * easp, *boosk, *haspe, *boask. Southern British English shows that the pattern is 
even more complex, in that a nucleus that contains $\mathbf{A}$ by itself can appear before fricative $+\mathrm{C}$ even when one of the final consonants does not contain A: clasp, task, draft are fine, ${ }^{*}$ cleesp,${ }^{*}$ toosk, ${ }^{*}$ dreeft are not.

Such patterns are easy to find and occur in languages other than English, too (Pöchtrager 2012). How to explain that particular behaviour, though, is more tricky. The most straightforward way, it seems, is to replace $\mathbf{A}$ by a particular structural configuration, as has been argued in Pöchtrager $(2006 ; 2012)$. In other words, expressions that were thought to contain $\mathbf{A}$ are structurally bigger than those without. In what follows we shall see that vowel reduction helps us to refine this idea: In fact, what should replace A-ness is empty structure. Emptiness is the crucial factor.

\section{The structure of vowels}

We will now lay out the basics of the theory I will work with here. Every nucleus consists of a head, which I will represent as an $x$-position (a terminal) with underlining (for headedness): $\mathrm{x}$. Such a head can (but does not have to) project up to two times, in which case the head or its projection combines with a sister $x$-position. This allows for the following options:

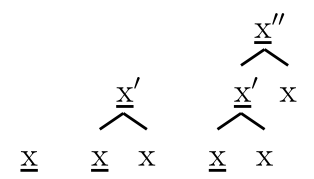

Furthermore, the structures in (5) can themselves be embedded as the sister to another, second nuclear head. This means that the maximal structure will look like this, with each head projecting twice: ${ }^{2}$

${ }^{2}$ I will stipulate that only one such embedding is possible, i.e., no infinite recursion. Note also that I will leave the choice of labels open at this point. That is, instead of speaking of an $x$-position that serves as the head, it would be more satisfactory to know what kind of head it is. Clearly, simply calling it a nuclear head (in any traditional sense) is not sufficient, in particular since we can have two of them on top of each other. 
(6)

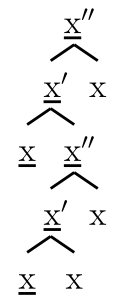

In those representations, the number of empty terminals corresponds to the openness of the vowel. The more empty terminals a vowel has, the more open it is. ${ }^{3}$ As (7) shows, [i] has one empty terminal, [ə] two, and [a] three, thus capturing the differences in openness between the three.

(7)

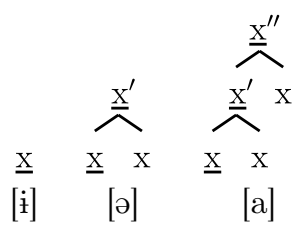

The structures in (7) give central vowels of varying degrees of openness. None of them have any elements in them, neither I to make them front nor $\mathbf{U}$ to make them round. Contrast this to (8), which shows various front vowels.

(8) a.

b.

c.

d.

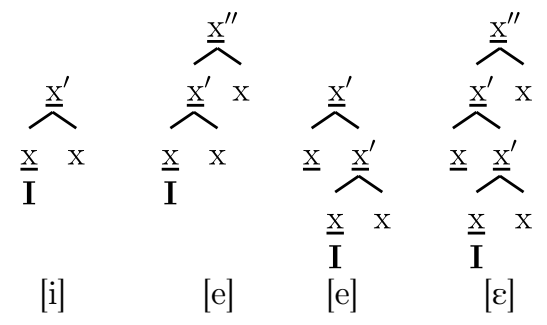

All the structures in (8) contain the element $\mathbf{I}$ somewhere in them, which makes all of them front. For restrictiveness, I will assume that annotating a position with an element is only possible if that position is a head. It might well turn out that that assumption is unjustified, but for the

${ }^{3}$ This is not entirely without problems; we will come back to this in section 5.1. 
sake of restrictiveness I will stick to it for the time being. ${ }^{4}$ As before in (7), openness is captured by the number of empty terminals in (8). Note furthermore that, given the way the mechanism is set up so far, there can be varying ways to build a structure with a grand total of, say, two layers. This is the reason why (8) contains two representations of the vowel [e]. We can either have a nuclear head that projects twice, going up to its maximum $\mathrm{x}^{\prime \prime}(8 \mathrm{~b})$ : We have a total of two layers and two empty terminals, both of which are non-heads. Alternatively, we have a nuclear head that projects only once, up to $\mathrm{x}^{\prime}$, but takes the projection of another nuclear head up to $\underline{x}^{\prime}$ as its complement (8c). Again, we have a total of two layers and two empty terminals, but this time one of them is a head. The representation of [e] in (8c) has two heads in total, one annotated and the other one unannotated, and this availability of two heads will be important later on, as it allows us to capture cross-linguistic differences. ${ }^{5}$ Finally, note that the vowel [i] in (8a) contains one empty terminal, viz., the sister to the annotated head. That vowel thus counts as the same height as [i] in (7), which also has one empty terminal, even though in the case of $[\mathrm{i}]$ that is the only terminal. ${ }^{6}$ In the same vein, either representation of $[\mathrm{e}]$ in $(8 \mathrm{~b}-\mathrm{c})$ has two empty terminals, making it the same degree of openness as [ə] in (7), etc. ${ }^{7}$

With those structures in place, we have already attained our initial goal: Vowel reduction is uniformly expressible as the removal of structure.

${ }^{4}$ Obviously, one would hope, however, that there is at least some restriction on the distribution of elements in order to curb the generative power of the system.

${ }^{5}$ That is, the structure in (8c) will be crucial; the role of (8b) and how its difference from (8c) can be exploited (if at all) is less clear at the moment. It might be linked to whether a language has vowel reduction at all, but this is very speculative.

${ }^{6}$ As a consequence, front rounded vowels, which contain both $\mathbf{I}$ and $\mathbf{U}$, will be more complex in structure, cf. Pöchtrager (2017b) for discussion.

${ }^{7}$ Aside from figuring in the calculation of the degree of openness, a terminal that is the sister to a nuclear head also plays a role in encoding tenseness/laxness, depending on who controls it. Thus, the non-head position of the vowel in (8a) can either be controlled by the nuclear head on the left, giving rise to a tense [i], or by a consonant to the right, giving us a lax vowel [I]. This derives, amongst other things, the (English) requirement that (stressed) lax vowels cannot occur finally or before another vowel; they must be followed by a consonant. The difference between tenseness/laxness is structural in the sense that it is about who controls a certain position, but not so much about whether the position is there at all, as in the cases looked at in this paper. Since tenseness/laxness is not immediately relevant for our purposes here, I will abstract away from it and ask the reader for patience until the publication of Pöchtrager \& Kaye (in preparation). 
Consider the structure of a mid-open vowel, a mid-close vowel and a high vowel in $\mathrm{BP}$, given in (9).

(9)

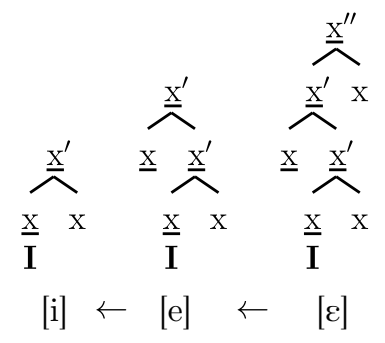

All we need to assume is that unstressed positions impose restrictions on space: In that way, we can explain both why in some languages length is affected (cf. Estonian), as well as why in some others it is quality (in BP). Both are results of the loss of structure. ${ }^{8}$

This applies in same fashion to the central vowels: The reduction of [a] is parallel to that of [e], as the comparison in (10) shows. The same position where [a] is disallowed, [e] is as well.

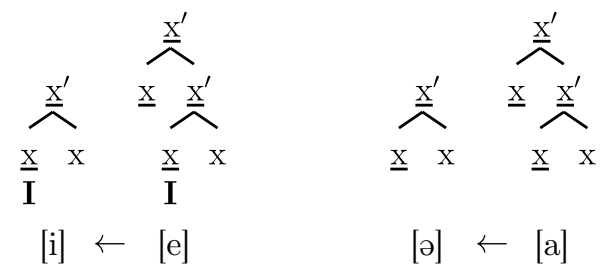

This reduction of [a] to [ə] is what we find in final position in BP, cf. the overview in (1). Removing a further layer would take the structure to nothing but a head, without any projection, in other words, to [i]. This can be observed in Turkish, where a form like kal-acák 's/he will stay' can be realised as $k a l[\mathrm{i}] c a ́ k .{ }^{9}$

${ }^{8}$ In GP 2.0, structure plays a central role and is not only assumed "on top of" segments, but continues within the traditional segment and in fact replaces it, cf. also Pöchtrager (2015a). This article only takes into account the structures responsible for quality; they are structures low down in the tree, where segments used to sit. That structure, so the argument, can be subject to reduction. Higher level structure, dealing with quantity, can of course also be pruned; this leads to shortening. For a detailed account of quantity cf. Pöchtrager (2006).

${ }^{9}$ Note that Turkish vowel reduction is not as straightforward as that of BP and EC; there are numerous morphosyntactic conditioning factors, calling its status as purely phonological into doubt, cf. Pöchtrager (2016) for further discussion. 
Comparison between $[\varepsilon]$ in (9) and [a] in (10) also makes clear that $[\varepsilon]$ has more layers of structure and is thus more susceptible to reduction than [a]. This is of course exactly what BP shows us. ${ }^{10}$ In terms of empty terminals, $[\varepsilon]$ and $[\mathrm{a}]$ have the same number (three) and would thus count as equal in openness. This is not exactly what the traditional classification looks like (mid-open vs. open), but notice that also in element accounts those vowels count as members of the same natural class, in that they are all headed by $\mathbf{A}$.

This approach to the representation of vowels is also consistent with earlier analyses put forward in GP 2.0, even though the structures proposed there will have to be updated.

For example, Jensen et al. (2009); Živanović \& Pöchtrager (2010) proposed an analysis of Putonghua onset-nucleus interactions as well as of the interactions between a nuclear head and adjacent glides (which I will transcribe as [i], [u]. There can be a glide preceding the nuclear head ("onglide") or following it ("offglide") or both. Onglides and offglides colour a schwa vowel that they flank. Thus, [i] plus schwa gives a front unrounded vowel, [u] plus schwa a back round vowel. On- and offglide are not equal in status, though. When both are present, the offglide takes precedence over the onglide. This has been taken as evidence that the offglide sits closer to the head than an onglide. Put differently, the offglide is like a complement to the nucleus, the offglide like a specifier, cf. the quoted works for details. A schema of this is given in (11).

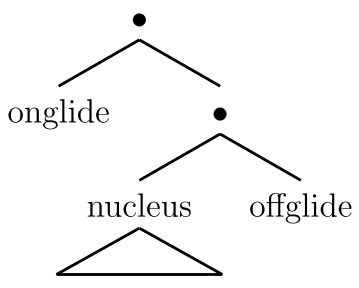

What is of interest in the context of the present article is the following: Colouring of schwa by the offglide (which sits low) yields $[\mathrm{e}] /[\mathrm{o}]$, while colouring by the onglide (high) yields $[\varepsilon] /[\supset]$. In other words, structural differences in where the trigger sits lead to a difference in the openness of

${ }^{10}$ One reviewer inquires whether in the current model [a] would always be predicted to be subject to reduction. The answer is "no"; it contains fewer layers than, say $[\varepsilon]$, and is thus only reduced when space is seriously at a premium as in the final position in BP. Reduction can take [a] to [ə], but does not have to; in the same fashion as reduction can take $[\mathrm{e}]$ to $[\mathrm{i}]$, but not necessarily so. 
the resulting vowel. An open-mid vowel is associated with more structure (trigger sits higher up) than a close-mid vowel. This is of course comparable to what we saw for EC and BP here: open-mid requires more structure than close-mid does.

Before we conclude this section, let us address one last issue, that of complexity. In the mid-1990's, research in GP had a strong interest in properties of vowel systems (Charette \& Göksel 1994; 1996; Cobb 1993; 1995; 1997; Kaye 2001; Kim 1996), in particular in the question of how to derive vowel systems from a small number of so-called Licensing Constraints. Those Licensing Constraints were meant to establish for each language how the universal set of vowel (and consonant) expressions could be cut down to exactly what we find, and it was also intended to explain how the make-up of a sound affected its phonological behaviour. The investigation of vowel systems shows that often, though not always, the presence of an open-mid vowel implies the presence of the corresponding close-mid vowel, but that the reverse does not necessarily hold true. For example, Finnish, French (at least in word-final position), Turkish, Estonian, and some varieties of German (in the long vowel system) allow an open-mid and a close-mid front vowel, but only a mid-close back vowel. It is interesting that it is the structurally bigger vowel (open-mid) that is lacking, suggesting that in some sense smaller structures (close-mid vowels) are more basic than bigger ones (open-mid vowels). However, given that the implicational relationship is only a statistical one, it might be much too early to jump to conclusions (such that a language would only allow the bigger structure if it also allows for the smaller one). One also has to keep in mind that the number of languages looked at here is rather restricted, and it is easy enough to find problematic cases: For example, Polish (Jassem 2003) has a five-vowel system whose mid vowels seem to be mid-open, not mid-closed. Likewise, looking back at (10), [a] and [e] are the same in terms of number of layers, yet typologically not equally unmarked. Given that, we have to be careful what kind of typological claims we want to make.

\section{Cross-linguistic variation}

\subsection{The position of elements}

Let us now address the issue of cross-linguistic variation in vowel reduction. The charts in (12) are a repetition of (1) and (2). 
(12) BP

\begin{tabular}{lr|c|c|c|c|c|c|c} 
a. & stressed & $i$ & $e$ & $\varepsilon$ & $a$ & $\supset$ & $o$ & $u$ \\
\hline b. & prestressed & $i$ & \multicolumn{2}{|c|}{$e$} & $a$ & \multicolumn{2}{|c}{$o$} & $u$ \\
\hline c. & unstressed final & \multicolumn{2}{|c|}{$i$} & ə & \multicolumn{2}{|c}{$u$}
\end{tabular}

EC

\begin{tabular}{r|c|c|c|c|c|c|c} 
strong & $i$ & $e$ & $\varepsilon$ & $a$ & $\partial$ & $o$ & $u$ \\
\hline weak & $i$ & \multicolumn{2}{|c|}{$\partial$} & \multicolumn{2}{|c}{$u$}
\end{tabular}

As was pointed out in the introduction, there is a difference between the two languages in that $\mathrm{BP}$ has a symmetrical reduction pattern, while that of EC is lopsided. Let us focus on the front vowels first. In BP, no matter how many layers we remove, we are stuck with a front vowel. In EC, on the other hand, $[\mathrm{e}],[\varepsilon]$ and [a] all merge as [ə]. For [a], this is of course not surprising, cf. (10). But how come that $[\mathrm{e}]$ and $[\varepsilon]$, two front vowels (which must contain the element I) end up as schwa (which does not contain I)? Clearly, there must be something more going on than just the removal of structure.

I submit that this difference can be expressed by allowing elements to occur in different positions in the tree. More concretely, I propose that I sits in the higher head in EC, but in the lower head in BP. This difference is illustrated in (14).

(13) $\mathrm{BP}$

EC

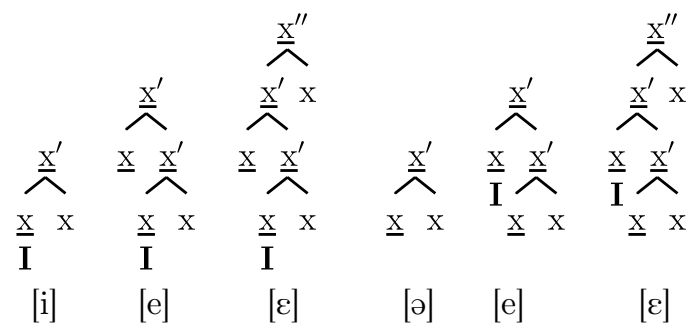

Let us focus on the representations for $[\varepsilon]$ in BP and EC. In terms of structure, both are the same. At the very bottom we have a head that projects once up to $\mathrm{x}^{\prime}$. This projection is in turn embedded in another projection; i.e., $\mathrm{x}^{\prime}$ is the sister to another, higher head, and this higher head projects twice. In total, we have two heads at our disposal and this is what is crucial. In BP, it is the lower head that is annotated with $\mathbf{I}$; in $\mathrm{EC}$, it is the higher head.

If we now assume that tree pruning starts from the top, then in EC I will be lost immediately: In EC, only the lowest layer of structure survives 
pruning, but since I sits higher up, not only will the structure be lost, but the annotation (the element $\mathbf{I}$ ) as well. Putting $\mathbf{I}$ in a high position explains why it is lost so fast and why the result is [ə]. In contrast, BP I is protected in its low position. We can safely take out the higher layers; as long as the lowest one remains, I will, too. The asymmetry in reduction patterns is derived.

Contrast this now to the back rounded vowels. In both languages, they remain round under reduction. This must mean that $\mathbf{U}$ remains safe even under reduction. The structures must then be as follows, for both BP and EC.

(14) BP \& EC

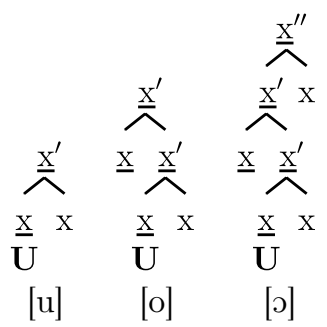

The only difference between the two languages is that in BP, depending on the prosodic position, either one or two layers of structure are removed. (Thus, depending on which unstressed position we find, either only [ $[$ ] is excluded or both [0] and [o].) This is identical to what we saw for the front vowels. And in like fashion, in EC it is (again) only the lowest layer that survives reduction (neither [o] nor [o] are allowed). Since $\mathbf{U}$ is low in both languages, it is unaffected by reduction.

While such a difference in the position of elements allows us to express differences in behaviour, it raises one obvious question: Is there evidence for such positioning independent of vowel reduction? Can we explain something else as well? This will be the subject matter of the next subsection.

\subsection{Interaction with consonants}

I submit that further support for the low position of $\mathbf{I}$ in BP can be adduced in the shape of alveolar palatalisation (which is present in at least some varieties of $\mathrm{BP}$ ), of which examples can be found in (15), cf. Cristófaro Alves da Silva (2003) for a GP account. 
(15) tia [tf'iə] 'aunt', dia [dz'iə] 'day', pode [p'odzi] 's/he can'

Palatalisation is nothing but the element $\mathbf{I}$ intruding into an onset. Interestingly, alveolar palatalisation is only triggered by one of three vowels containing $\mathbf{I}$, viz., [i], while $[\mathrm{e}]$ or $[\varepsilon]$ cannot trigger it. Under our present proposal $[\mathrm{e}] /[\varepsilon]$ in $\mathrm{BP}$ (though not EC) both have $\mathbf{I}$ at the very bottom of the structure, cf. (14). In BP $[\mathrm{e}] /[\varepsilon], \mathbf{I}$ is therefore shielded off by a lot of structure on top of it: $[\mathrm{e}]$ has one layer of empty structure on top, $[\varepsilon]$ two layers, but [i] none, cf. (9). This would explain why an $\mathbf{I}$ in [i] can palatalise a preceding alveolar, while $[\mathrm{e}] /[\varepsilon]$ cannot: In the case of $[\mathrm{e}] /[\varepsilon]$ there is simply too much structure on top that $\mathbf{I}$ would need to cross in order to palatalise a preceding consonant, while $\mathbf{I}$ can get out of [i] quite easily. In other words, the structural approach to vowels also allows us to make sense of their interaction with consonants. Now, it would be perfect if EC also had a palatalisation process of kinds, so as to test whether the right predictions are made there, too. Sadly, life is never that good for a phonologist.

A similar idea, viz., that the position of an element determines its visibility to the outside world, has also been made use of in the GP 2.0 analysis of Putonghua onset-nucleus interactions (Jensen et al. 2009; Živanović \& Pöchtrager 2010). In short, an element in an onset is only visible to the nucleus if that element sits in the specifier of the onset, but not if it sits further down. To illustrate, take the onsets $\left[\mathrm{g}^{\mathrm{w}}\right]$ and $[\mathrm{p}]$. Both contain the element $\mathbf{U}$. There is, however, an asymmetry in that [pau] is licit but $*\left[g^{\mathrm{w}} \mathrm{au}\right]$ is not. The ungrammaticality of $*\left[g^{\mathrm{w}} \mathrm{au}\right]$ can be derived from phonological Binding Theory (Pöchtrager 2009a; 2015b; Živanović \& Pöchtrager 2010) which regulates the distribution of elements in a phonological domain: $\mathrm{An} \mathbf{U}$ in onset position interferes with the offglide of [au]. The $\mathbf{U}$ in $[\mathrm{p}]$ is buried deep down and as such unproblematic. In $\left[\mathrm{g}^{\mathrm{w}}\right]$ the $\mathbf{U}$ sits high up in the specifier and therefore is visible. (This is even reflected in the realisation of those consonants, with the $\mathbf{U}$ in $\left[\mathrm{g}^{\mathrm{w}}\right]$ coming out as labiovelarisation.)

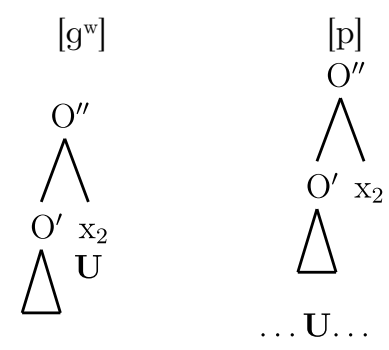


Allowing for a given element to sit in different positions raises the issue of how the correct representation can be learnt. In the case of $\left[g^{\mathrm{w}}\right]$ vs. $[\mathrm{p}]$ in (16), the different arrangement of $\mathbf{U}$ corresponds to a clearly discernible acoustic difference and thus poses no problem. In the case of [e] in BP vs. EC (14) there is, to the best of my knowledge, no acoustic difference; yet the argument here is that $\mathbf{I}$ sits in different positions. The child acquiring the language in question would then have to rely on clues from behaviour, in particular reduction patterns and the interaction with flanking consonants. Openness (number of empty terminals) and frontness (element I) can presumably be gleaned from the signal alone, but their arrangement in a structure will depend on behaviour.

\subsection{Other languages}

Let us now look at some other cases of vowel reduction to see whether and how easily the proposal can be applied to those. In fact, much of what we are going to see is just a variation on a common theme. Italian (17) seems simply like the first stage of BP, while Bulgarian (18), cf. Harris (2005), looks like the last stage of BP.

\begin{tabular}{r|c|c|c|c|c|c|c} 
stressed & $i$ & $e$ & $\varepsilon$ & $a$ & $o$ & $o$ & $u$ \\
\hline unstressed & $i$ & $e$ & $a$ & $o$ & $u$
\end{tabular}

\begin{tabular}{r|c|c|c|c|c|c} 
strong & $i$ & $e$ & $a$ & a & $o$ & $u$ \\
\hline weak & $i$ & a & \multicolumn{2}{c}{$u$}
\end{tabular}

In other words, the reduction patterns are a subset of the patterns we have already seen.

Russian (Timberlake 2004) is of interest in that it seems to have $\mathbf{I}$ in a low position but $\mathbf{U}$ in a higher position, so the reverse of what we have seen for those two elements in EC.

$$
\begin{array}{r|c|c|c|c|c|c}
\text { strong } & \dot{t} & i & e & a & o & u \\
\hline \text { weak } & \dot{i} & & i & \partial / \Lambda & u
\end{array}
$$

Since I survives vowel reduction $([\mathrm{e}] \rightarrow[\mathrm{i}])$ while $\mathbf{U}$ does not $([\mathrm{o}] \rightarrow[\mathrm{\partial} / \Lambda])$ we have to assume that $\mathbf{I}$ is low and $\mathbf{U}$ high. The low position of $\mathbf{I}$ in [e] is also backed up by its failure to consistently trigger palatalisation, analogously to BP. 


\subsection{Northern/Northeastern BP}

Let us return to BP for a moment. Obviously, "Brazilian Portuguese" is a rather vague term, as it encompasses several varieties. Nevins (2012) argues that in Northern/Northeastern BP (N/NE-BP, itself not very precise) $[\varepsilon] /[\mathrm{e}]$ merge as $[\varepsilon]$ and $[0] /[\mathrm{o}]$ as $[0]$. Given the assumption made in this article, this is a problem, since the mid-open vowels are bigger than the mid-close ones, and vowel reduction is expressed by the removal of layers of structure.

However, the facts are not as straightforward, and they do not necessarily suggest the conclusion Nevins arrives at. What N/NE-BP really seems to have is a kind of vowel harmony (Cobb 2003; Segundo 1993):

$\begin{array}{llll}{[\mathrm{k} \text { 'cbri }]} & \text { 'break' } & {[\mathrm{k} \text { 'olu }]} & \text { 'I glue' } \\ {[\mathrm{kebr} \text { ava }]} & \text { 'I used to break' } & {[\mathrm{kol} \text { 'ava }]} & \text { 'I used to glue' } \\ {[\text { kebr'ej }]} & \text { 'I broke' } & {[\mathrm{kol} \text { 'ej }]} & \text { 'I glued' }\end{array}$

It is true that $[\varepsilon] /[\supset]$ can be found in prestressed position, but then seems to require a following $[\varepsilon] /[0] /[\mathrm{a}]$. As Albano $(1999,42)$ points out, vowel reduction in $\mathrm{N} / \mathrm{NE}-\mathrm{BP}$ "interage com processos de abaixamento que resultam em $[\varepsilon]$ e $[\rho]$ " ("interacts with lowering processes that result in $[\varepsilon]$ and [o]").

\section{Extensions}

\subsection{Vowel inventories}

Let us finally address the generative power of our system which allows a total of four layers. In BP and EC we had seen a maximum of three layers, so one could ask if four are really ever needed. The answer comes from languages with rich vowel inventories such as Danish (Basbøll 2005; Basbøll \& Wagner 1985).

$\begin{array}{llll}\text { line } & {[\mathrm{i}:]} & \text { 'lead' } & 1 \text { layer \& } \mathbf{I} \\ \text { Lene } & {[\mathrm{e}]} & \text { (personal name) } & 2 \text { layers \& } \mathbf{I} \\ \text { loene } & {[\mathrm{\varepsilon :}]} & \text { 'to lean' } & 3 \text { layers \& } \mathbf{I} \\ \text { Lane } & {[æ:]} & \text { (personal name) } & 4 \text { layers \& } \mathbf{I} \\ \text { arne } & {[\mathrm{a:}]} & \text { 'stove' } & 4 \text { layers }\end{array}$

Danish seems to require up to four layers: The first four vowels in (21) all contain I, they only differ in openness. The last vowel, [a: , differs from [æ:] 
only in that the latter contains I unlike the former. Given that, it seems natural to assume that the representation of [a: contains four layers as well, even if that makes it different from $a$ in languages like BP and EC. ${ }^{11}$ In fact, Basbøll and Wagner (1985) distinguish three $a$-vowels plus [e], suggesting that even for vowels without elements four possibilities (and hence one, two, three or four layers) might be needed. ${ }^{12}$

Let us finally consider smaller vowel inventories. The classic five-vowel system would only require the projection of one single head: The high vowels $i / u$ would have one layer of structure, all others two. There is no need to go beyond that, as (22) shows.

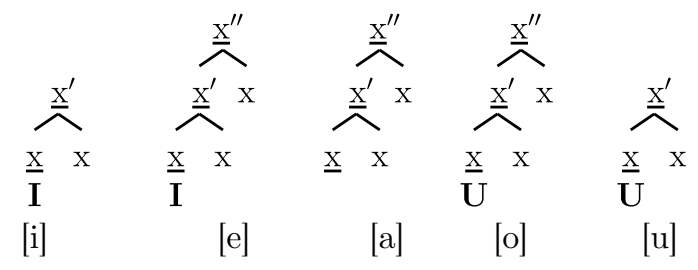

\subsection{Consonants}

The proposal made here can also be extended to consonants. At least in some flavours of the theory, $\mathbf{A}$ is the element encoding coronality (Cyran 1997; Goh 1997; Kaye 2000), i.e., the same element that characterises nonhigh vowels. Support for that claim came from the analysis of English intrusive $r$ (Broadbent 1991; 1999), which requires the nucleus preceding the insertion site to contain A: Shah-[r]-of Persia (where the final vowel of Shah contains A) vs. Rabbi-*[r]-of Budapest (where the final vowel of Rabbi does not). Under the assumption that $r$ is nothing but the element $\mathbf{A}$ in onset position, intrusive $r$ can simply be interpreted as a special case of glide formation: An element spreads from a nucleus to an empty onset position, like see-[j]-ing in some varieties of English. (Here it is of course an I that spreads from a preceding nucleus into an onset position.) This allowed for a non-arbitary account of intrusive $r$. Furthermore, corroboration also came from the observation that $\mathbf{R}$ (the coronal element employed

${ }^{11}$ Schane (1984) deals with a similar problem in Particle Phonology. For him, the lowest vowel contains at least as many a-particles as any other vowel in the system, meaning that the representation of $a$ can vary according to the system.

12 "Might" because the distribution of those $a$-vowels is fairly complex and their phonological status would require a further study. 
in the very early days of the theory) did not seem to occur in nuclear positions. Equating $\mathbf{R}$ with $\mathbf{A}$ filled that gap.

The removal of $\mathbf{A}$ from the set of elements also has consequences for consonants. If the replacement is empty structure, then this will have to be true of coronals in like fashion: they will have to be bigger in size than noncoronals. This has been argued for elsewhere (Pöchtrager 2010; 2013a;b; 2017a) on the basis of the fact that coronals always seem to be involved with bigger structures, as if they provided the room that can be used by other objects around them, cf. section 2. The bigger size of coronals also explains a crucial aspect in the lenition (tapping/glottalisation) of coronal stops in English. In order to fully appreciate this, one needs to keep in mind that in GP 2.0, several elements have been replaced by (different types of) structure, amongst them also the stop element $\mathbf{P}$ (Pöchtrager 2006), building on an earlier proposal by Jensen (1994). This makes stops bigger than fricatives and approximants. Combined with the replacement of $\mathbf{A}$ by structure, this makes coronal stops the biggest objects of the system, and thus it is unsurprising that they are singled out for lenition.

This does not imply that only coronals could be targeted by lenition. For example, Danish (Harris 1999) shows foot-internal lenition of stops irrespective of their place. However, given the representation of stops (bigger than other manners), they are still the biggest objects of the system, suggesting that Danish is simply less "tolerant" about what is allowed in prosodically weak positions than English is. This is of course similar to the comparison between EC and BP: In (certain) unstressed positions the latter does allow slightly bigger structures than the former. ${ }^{13}$

The expression of voicelessness (and by extension high tone) used to be covered by the element $\mathbf{H}$, which has also fallen victim to a structural reinterpretation, based on facts from English and Estonian (Pöchtrager 2006). And again, a language like Danish shows us that voicelessness can be restricted to prosodically strong positions and absent from weak ones.

Given that coronals, stops, and voiceless objects are common targets of lenition and that they have all been replaced by structure, it is somewhat

${ }^{13}$ I am aware that velars are also common lenition targets. However, in the cases that I am more intimately familiar with, the Baltic-Finnic languages (Holman 1975; Pöchtrager 2008) and Turkish (Inkelas 2011; Pöchtrager 2016), lenition of velars is heavily morphologised and the result of diachronic change, unlike in English tapping/ glottalisation. If there are indeed cases of velar lenition that are regular phonological processes, size cannot be the crucial factor, since velars are smaller than coronals. However, velars (just like coronals) are devoid of elements, which must be the reason why both are commonly identified as unmarked, and might well be (part of) the reason why they are weak. 
tempting to conjecture that lenition of whatever kind might always be about structural size. Loss of melody would then only ever be "collateral damage" (as we saw in EC). While it might be too early to assert such a proposal, it certainly holds the promise of uniting a number of phenomena. One very obvious problem that remains is the treatment of nasal stops, which in GP 2.0 are structurally as complex as plosives, yet they behave differently under lenition.

\section{Conclusions}

This article has claimed that the openness of a vowel should be encoded by empty positions, which therefore entails more structure. As a consequence, vowel reduction is expressible as the removal of that structure. This basic idea has certain parallels to two other models. Firstly, there is Particle Phonology (Schane 1984), which allows the multiple occurrence of the particle a encoding openness. A close-mid vowel could be represented by $\mathbf{a}$, an open-mid vowel by aa, etc. This can be repeated as many times as needed. Secondly, there are also parallels to Clements (1991), where the feature [open] could be split (into [open 1 , [open 2 , etc.) to allow for as many degrees of height as needed. In fact, this freedom is a problem that both approaches share: To the extent that there is no limit on how many times a can be repeated or [open] be split, the systems overgenerate. This is exactly the reason why in section 3 we proposed that a nuclear head should be restricted to maximally two projections and that there can be maximally two nuclear heads on top of each other. While such a blunt restriction is clearly a stipulation at this point, at least it curbs overgeneration. As we saw in the discussion of Danish, four layers of structure are a good candidate as an upper limit.

The approach argued for in this article also differs from the other two in that it extends easily to other kinds of weakening phenomena. The feature [open] is clearly geared towards vowels only and as such limited in its applicability. Broadbent (1999) uses the a particle to characterise coronals (similar to the element $\mathbf{A}$ ), which would allow bringing out the commonalities between vowel reduction and tapping (which Broadbent does not attempt to do). The GP 2.0 approach makes that connection and goes still one step further, however, in that reduction of structure can also be found in purely length-related phenomena (as in Estonian).

In addition to all of this, the article has also tried to argue that the position of an element determines the behaviour of the object it is part of 
and thus leads to cross-linguistic variation. It remains to be seen to what extent this brings us closer to a general theory of lenition/reduction.

\section{Acknowledgements}

Thanks to the Boğaziçi University Research Fund/Bilimsel Araştırma Projeleri (Grant \#8781) for financial support. Thanks to the audiences of OCP13, MFM23 and IATL32, as well as to two anonymous reviewers for very valuable feedback. All remaining errors are my own.

\section{References}

Albano, Eleonora Cavalcante. 1999. O Português Brasileiro e as Controvérsias da Fonética Atual: Pelo Aperfeiçoamento da Fonologia Articulatória. DELTA: Documentação de Estudos em Lingüística Teórica e Aplicada 15. 23-50.

Anderson, John and Colin J. Ewen. 1987. Principles of Dependency Phonology. Cambridge: Cambridge University Press.

Backley, Phillip. 2011. An introduction to Element Theory. Edinburgh: Edinburgh University Press.

Basbøll, Hans. 2005. The phonology of Danish. Oxford: Oxford University Press.

Basbøll, Hans and Johannes Wagner. 1985. Kontrastive Phonologie des Deutschen und Dänischen. Segmentale Wortphonologie und -phonetik. Tübingen: Max Niemeyer.

Broadbent, Judith M. 1991. Linking and Intrusive r in English. UCL Working Papers in Linguistics, 3. 281-301.

Broadbent, Judith M. 1999. A new approach to the representation of coronal segments. In S. J. Hannahs and M. Davenport (eds.) Issues in phonological structure. Papers from an international workshop. Amsterdam \& Philadelphia: John Benjamins. 1-25.

Charette, Monik and Aslı Göksel. 1994. Vowel harmony and switching in Turkic languages. SOAS Working Papers in Linguistics \& Phonetics 4. 29-56.

Charette, Monik and Aslı Göksel. 1996. Licensing constraints and vowel harmony in Turkic languages. SOAS Working Papers in Linguistics \& Phonetics 6. 1-25.

Clements, Nick. 1991. Vowel height assimilation in Bantu languages. In K. Hub-Bard (ed.) BLS 17S: Proceedings of the Special Session on African Languages Structures. Berkeley, CA: Berkeley Linguistic Society. 25-64.

Cobb, Margaret. 1993. Licensing constraints and vowel harmony in Uyghur. SOAS Working Papers in Lingusitics and Phonetics 3. 40-64.

Cobb, Margaret. 1995. Vowel harmony in Zulu and Basque: The interaction of licensing constraints, $\mathrm{H}-$ Licensing and constituent structure. SOAS Working Papers in Lingusitics and Phonetics 5. 23-39.

Cobb, Margaret. 1997. Conditions on nuclear expressions in phonology. Doctoral dissertation. School of Oriental and African Studies, Department of Linguistics, University of London. 
Cobb, Margaret. 2003. Government Phonology and the vowel harmonies of Natal Portuguese and Yoruba. In Ploch (2003, 223-242).

Cristófaro Alves da Silva, Thaïs. 1992. Nuclear phenomena in Brazilian Portuguese. Doctoral dissertation. School of Oriental and African Studies, University of London.

Cristófaro Alves da Silva, Thaïs. 2003. Palatalisation in Brazilian Portuguese. In Ploch (2003, 243-257).

Cyran, Eugeniusz. 1997. Resonence elements in phonology. A study in Munster Irish (PASE Studies and Monographs 3). Lublin: Wydawnictwo Folium.

Goh, Yeng-Seng. 1997. The segmental phonology of Beijing Mandarin. Crane: Taipei.

Harris, John. 1997. Licensing inheritance: An integrated theory of neutralisation. Phonology 14. 315-370.

Harris, John. 1999. Release the captive coda: The foot as a domain of phonetic interpretation. UCL Working Papers in Linguistics 11. 165-194.

Harris, John. 2005. Vowel reduction as information loss. In P. Carr, J. Durand and C. J. Ewen (eds.) Headhood, elements, specification and contrastivity: Phonological papers in honour of John Anderson. Amsterdam \& Philadelphia: John Benjamins. 119-132.

Harris, John and Geoff Lindsey. 1995. The elements of phonological representation. In J. Durand and F. Katamba (eds.) Frontiers of phonology: Atoms, structures, derivations. Harlow: Longman. 34-79.

Harris, John and Geoff Lindsey. 2000. Vowel patterns in mind and sound. In N. BurtonRoberts, P. Carr and G. Docherty (eds.) Phonological knowledge: Conceptual and empirical issues. Oxford: Oxford University Press. 185-205.

Holman, Eugene. 1975. Allomorphic and dialectal cohesion in the light of Baltic-Finnic grade alternation. Helsinki: University of Helsinki.

Inkelas, Sharon. 2011. Another look at velar deletion in Turkish. In E. Erguvanlı Taylan and B. Rona (eds.) Puzzles of language. Essays in honour of Karl Zimmer. Wiesbaden: Harrassowitz. 37-53.

Jassem, Wiktor. 2003. Polish. Journal of the International Phonetic Association 33. 103107.

Jensen, Sean. 1994. Is $?$ an element? Towards a non-segmental phonology. SOAS Working Papers in Linguistics and Phonetics 4. 71-78.

Jensen, Sean, Jonathan Kaye, Markus Alexander Pöchtrager and Sašo Živanovič. 2009. GP 2.0 and Putonghua, too. Paper presented at the 6th Government Phonology Round Table, Piliscsaba, April 25, 2009.

Kaye, Jonathan. 2000. A user's guide to Government Phonology (GP). Manuscript.

Kaye, Jonathan D. 2001. Working with licensing constraints. In K. Dziubalska-Kołaczyk (ed.) Constraints and preferences. Berlin \& New York: Mouton de Gruyter. 251-268.

Kaye, Jonathan D. and Markus Alexander Pöchtrager. 2009. GP 2.0. Paper presented at the 6th Government Phonology Round Table, Piliscsaba, April 25, 2009.

Kim, Seon Jung. 1996. The representations of Korean phonological expressions and their consequences. Doctoral dissertation. School of Oriental and African Studies, University of London.

Lehiste, Ilse. 1965. Juncture. In E. Zwirner and W. Bethge (eds.) Proceedings of the Fifth International Congress of Phonetic Sciences, University of Münster. Basel: S. Karger. $172-200$. 
Mateus, Maria Helena and Ernesto d'Andrade. 2000. The phonology of Portuguese. Oxford: Oxford University Press.

Nevins, Andrew. 2012. Vowel lenition and fortition in Brazilian Portuguese. Letras de Hoje 47. $228-233$.

Ploch, Stefan (ed.). 2003. Living on the edge: 27 papers in honour of Jonathan Kaye. Berlin \& New York: Mouton de Gruyter.

Pöchtrager, Markus Alexander. 2006. The structure of length. Doctoral dissertation. Universität Wien.

Pöchtrager, Markus Alexander. 2008. Finnish consonant gradation. In J. B. de Carvalho, T. Scheer and P. Ségéral (eds.) Lenition and fortition. Berlin \& New York: Mouton de Gruyter. 357-385.

Pöchtrager, Markus Alexander. 2009a. Diphthong ${ }_{i}, e_{i}$ know thyself ${ }_{i}$. Binding in phonology. Paper presented at the 17th Manchester Phonology Meeting, 28-30 May 2009.

Pöchtrager, Markus Alexander. 2009b. Syntaxy government phonology. Paper presented at Generative Approaches to Contrastive Linguistics 3 (GACL 3), 15-16 May 2009, Nicosia.

Pöchtrager, Markus Alexander. 2010. The structure of A. Paper presented at the 33rd GLOW Colloquium, 13-16 April 2010, Wrocław.

Pöchtrager, Markus Alexander. 2012. Deconstructing A. Paper presented at the MFM Fringe Meeting on Segmental Architecture, 23 May 2012, Manchester.

Pöchtrager, Markus Alexander. 2013a. Alveolars, size and lenition. Paper presented at the 21st Manchester Phonology Meeting, 23-25 May 2013.

Pöchtrager, Markus Alexander. 2013b. On A. Paper presented at A Workshop on Melodic Representation, 12 March 2013, London.

Pöchtrager, Markus Alexander. 2015a. Beyond the segment. In E. Raimy and C. Cairns (eds.) The segment. Hoboken, NJ: Wiley. 44-64.

Pöchtrager, Markus Alexander. 2015b. Binding in phonology. In H. van Riemsdijk and M. van Oostendrop (eds.) Representing structure in phonology and syntax. Berlin \& New York: Mouton de Gruyter. 255-275.

Pöchtrager, Markus Alexander. 2016. Is there phonological vowel reduction in Turkish? In M. Güven, D. Akar, B. Öztürk and M. Kelepir (eds.) Exploring the Turkish Linguistic Landscape: Essays in honor of Eser Erguvanll Taylan. Amsterdam \& Philadelphia: John Benjamins. 21-39.

Pöchtrager, Markus Alexander. 2017a. It's all about size. In P. Szigetvári (ed.) 70 snippets to mark Ádám Nádasdy's 70th birthday. Budapest: Department of English Linguistics, Eötvös Loránd University. http://seas3.elte.hu/nadasdy70

Pöchtrager, Markus Alexander. 2017b. Transparent vowels: Small cogs in large machines. Paper presented at the 25th Manchester Phonology Meeting, 25-27 May 2017.

Pöchtrager, Markus Alexander and Jonathan Kaye. 2013. GP2.0. SOAS Working Papers in Linguistics and Phonetics 16. 51-64.

Pöchtrager, Markus Alexander and Jonathan Kaye. in preparation. The grand unified theory of vowels.

Raun, Alo and Andrus Saareste. 1965. Introduction to Estonian linguistics. Wiesbaden: Otto Harrassowitz. 
Schane, Sanford A. 1984. The fundamentals of Particle Phonology. Phonology Yearbook 1. $129-155$.

Segundo, Silvia de Oliveira. 1993. Stress and related phenomena in Brazilian (Natal) Portuguese. Doctoral dissertation. School of Oriental and African Studies, University of London.

Timberlake, Alan. 2004. A reference grammar of Russian. Cambridge: Cambridge University Press.

Wetzels, W. Leo. 1995. Mid-vowel alternations in the Brazilian Portuguese verb. Phonology 12. 281-304.

Wheeler, Max W. 2005. The phonology of Catalan. New York: Oxford University Press.

Živanović, Sašo and Markus Alexander Pöchtrager. 2010. GP 2.0 and Putonghua too. Acta Linguistica Hungarica 57. 357-380. 